Article

\title{
The Impact of Power Switching Devices on the Thermal Performance of a 10 MW Wind Power NPC Converter
}

\section{Ke Ma* and Frede Blaabjerg}

Department of Energy Technology, Institute of Energy Technology, Aalborg University, Pontoppidanstraede 101, DK-9220 Aalborg East, Denmark; E-Mail: fbl@et.aau.dk

* Author to whom correspondence should be addressed; E-Mail: kema@et.aau.dk; Tel.: +45-2136-9447.

Received: 23 May 2012; in revised form: 25 June 2012 / Accepted: 9 July 2012 /

Published: 17 July 2012

\begin{abstract}
Power semiconductor switching devices play an important role in the performance of high power wind energy generation systems. The state-of-the-art device choices in the wind power application as reported in the industry include IGBT modules, IGBT press-pack and IGCT press-pack. Because of significant deviation in the packaging structure, electrical characteristics, as well as thermal impedance, these available power switching devices may have various thermal cycling behaviors, which will lead to converter solutions with very different cost, size and reliability performance. As a result, this paper aimed to investigate the thermal related characteristics of some important power switching devices. Their impact on the thermal cycling of a $10 \mathrm{MW}$ three-level Neutral-Point-Clamped wind power converter is then evaluated under various operating conditions; the main focus will be on the grid connected inverter. It is concluded that the thermal performances of the 3L-NPC wind power converter can be significantly changed by the power device technology as well as their parallel configurations.
\end{abstract}

Keywords: wind power; power switching devices; inverter; thermal performance

\section{Introduction}

The European Union has committed itself to source 20\% of its energy from renewables by 2020 [1]. As the most promising candidate, wind energy production integrated into the power grid is booming all over the World. Meanwhile, the power capacity of a single wind turbine is continuously increasing to 
reduce the price pr. produced $\mathrm{kWh}$, and $7 \mathrm{MW}$ offshore wind turbines have already been presented on the market [2-4]. Consequently, due to much more significant impact on the power grid and higher cost after a failure than ever before, the wind power generation system is required to be more reliable and at the same time be controllable even under adverse natural environment or grid disturbances.

In order to meet the growing reliability and power controllability challenges, configurations for wind power generation have evolved from the no power electronic converter based system in the 1980s to the state-of-the-art full power electronic converter system, as indicated in Figure 1. This is mainly because the full power converter system has full power controllability of the entire generated power from the wind turbines. Meanwhile, the simplified or eliminated gearbox and slip-ring can lead to more reliable mechanical structure of the system [3].

Figure 1. Evolution of wind turbines and power converters in the last 30 years (blue color indicates power level of converters in proportion to the wind turbines) [5].

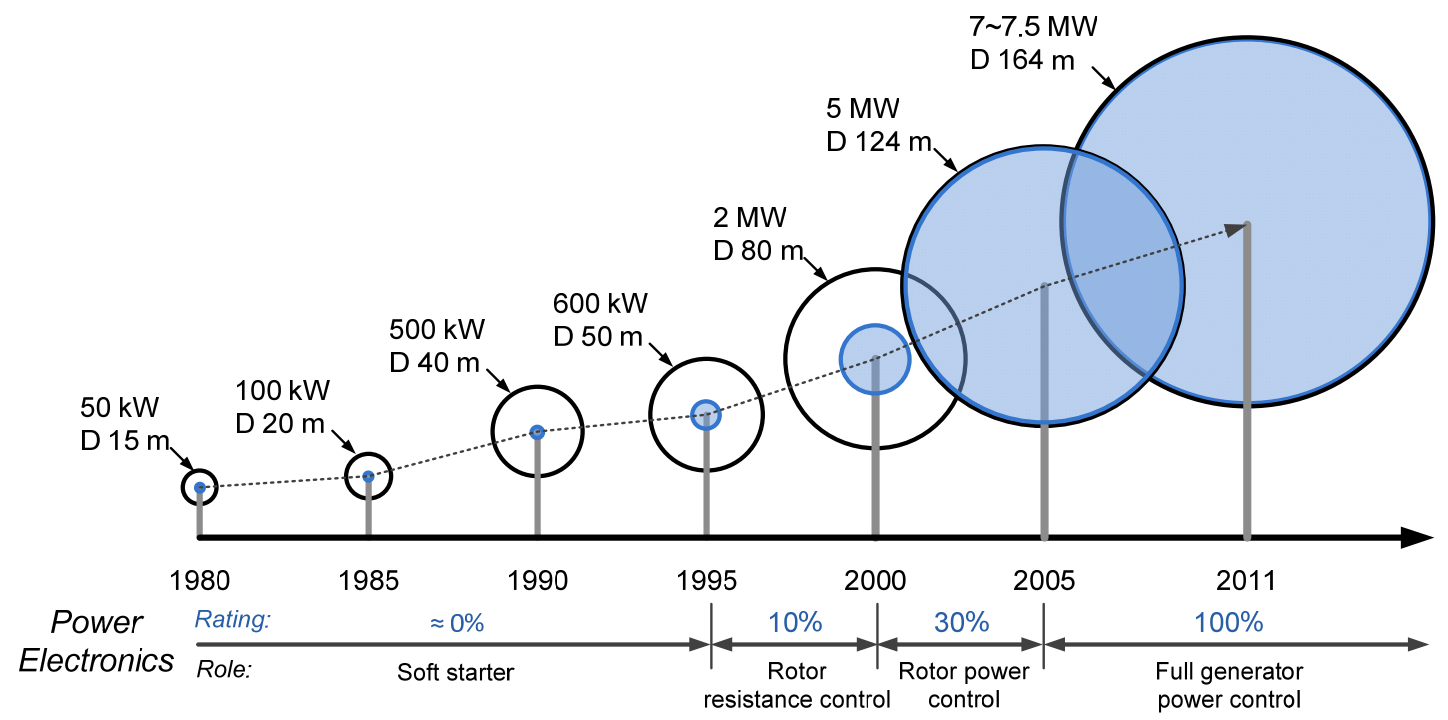

Nevertheless, the larger capacity power electronic converters introduced with more stressed and expensive power semiconductors may trade off the lifetime and cost performance of the electrical parts in the full power converter based generation system. As a result, the reliability and cost related characteristics are critical when choosing power switching devices for the modern wind power converters.

The dominant power switching device choices as reported in the wind power industrial application are based on module packaging Insulated Gate Bipolar Transistor (IGBT), press-pack packaging IGBT and the press-pack packaging Integrated Gate Commutated Thyristor (IGCT). The three power semiconductor devices have quite different characteristics and are generally compared in Table 1 [5]. The module packaging technology for IGBT has a longer track record of applications and fewer mounting regulations. However because of the soldering and bond-wire connection of internal chips, module packaging devices may suffer from larger thermal resistance, lower power density and higher failure rates [6]. The press-pack packaging technology improves the connection of chips by direct press-pack contacting, which leads to improved reliability (yet to be scientifically proven but known from industrial experience), higher power density (easier stacking for series connection) and better cooling capability with the disadvantage of higher cost compared to the module packaging devices. 
Press-pack IGCTs were introduced into the medium voltage converters in the 1990s and are already becoming state of the art in high power electric drives (e.g., for oil and gas application) but have not yet been significantly mass adopted in the wind turbine industry [6-8].

Table 1. Dominant power switching devices for modern wind power converters.

\begin{tabular}{lccc}
\hline Characteristics & IGBT module & IGBT Press-pack & IGCT Press-pack \\
\hline Power Density & Moderate & High & High \\
Reliability & Moderate & High & High \\
Cost & Moderate & High & High \\
Failure mode & Open circuit & Short circuit & Short circuit \\
Easy maintenance & + & - & - \\
Insulation of heat sink & + & - & - \\
Snubber requirement & - & - & + \\
Thermal resistance & Moderate & Small & Small \\
Switching loss & Low & Low & High \\
Conduction loss & High & High & Low \\
Gate driver & Small & Small & Large \\
Major manufacturers & Infineon, Mitsubishi & Westcode, ABB & ABB \\
Medium voltage ratings & ABB, Semikron, Fuji & & \\
Max. current ratings & $1.3 \mathrm{kV} / 4.5 \mathrm{kV} / 6.5 \mathrm{kV}$ & $2.5 \mathrm{kV} / 4.5 \mathrm{kV}$ & $4.5 \mathrm{kV} / 6.5 \mathrm{kV}$ \\
\hline
\end{tabular}

Note: + means yes or better, - means no or worse.

According to [6,9-12], the thermal cycling behavior inside the power switching devices is one of the key failure mechanisms and is closely related to its life time as well as the cost/size of the corresponding heat sink system. Therefore, it is interesting to investigate the thermal cycling related characteristics of the three important power switching devices applied in the wind power application. In this paper, the impact of the three important power switching devices on the thermal cycling of a $10 \mathrm{MW}$ three-level Neutral-Point-Clamped wind power converter are evaluated under various operating conditions; the main focus will be on the grid connected inverter.

\section{Wind Power Converter for Case Study}

It is expected that $10 \mathrm{MW}$ wind turbines with full-scale power converters will be the next long-term target to be conquered according to the current technology trends [2-5]. In most cases, the multi-level converter topologies will be expected to handle such high power with medium voltage ratings [13]. As the most commercialized multilevel converter [14,15], three-level neutral-point-clamped (3L-NPC) topology seems to be a promising candidate [16,17], as shown in Figure 2, where $\mathrm{T}_{\text {out }}$ represents the outer switch, $D_{\text {out }}$ is the outer freewheeling diode, $T_{\text {in }}$ is the inner switch, $D_{\text {in }}$ is the inner freewheeling diode, and $\mathrm{D}_{\mathrm{npc}}$ is the clamping diode. This configuration is selected for the analysis in this paper. 
Figure 2. A back-to-back three level neutral-point-clamped wind power converter system.

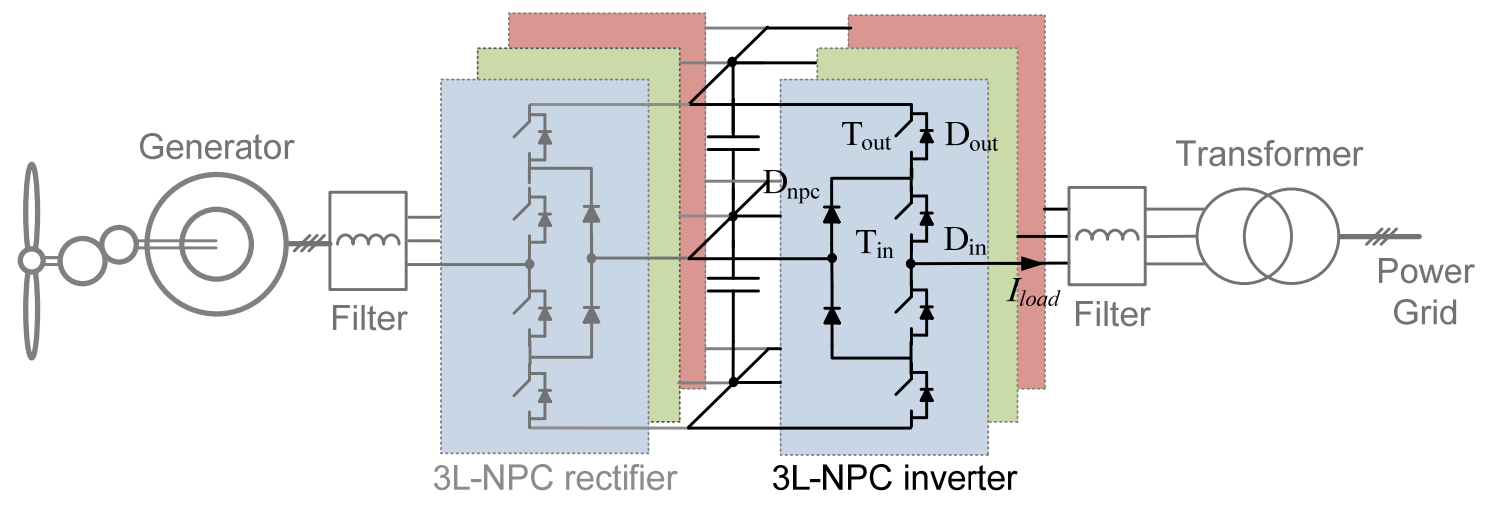

A $10 \mathrm{MW}$ medium-voltage 3L-NPC wind power inverter is first designed for a case study. As summarized in Table 2 [18], all of the power devices have the commutated voltage of $2.8 \mathrm{kV}$ in order to utilize the dominant $4.5 \mathrm{kV}$ high-power semiconductors available on the market, and the rated DC bus voltage can be determined at $5.6 \mathrm{kV}$. Normal Phase-Disposition Sinusoidal-Pulse-Width-Modulation method for the 3L-NPC converter is applied. The carrier frequency is typically designed to be $800 \mathrm{~Hz}$ in order to reach an acceptable switching loss and respect the switching frequency limitation for the high power semiconductor devices. The output filter inductance is designed to limit the maximum voltage drop on inductor as 0.2 p.u.; the filter capacitance is not taken into account in this paper. For simplicity of analysis and to keep the analysis focus on the power loss and thermal behavior of the power semiconductors, the power grid is considered as three ideal AC voltage sources and the DC bus capacitance is assumed high. The used generator and wind turbine models can be found from $[19,20]$.

Table 2. Rated parameters of $10 \mathrm{MW} 3 \mathrm{~L}-\mathrm{NPC}$ wind power inverter for case study.

\begin{tabular}{lc}
\hline Converter items & Parameters \\
\hline Rated output active power $P_{o}$ & $10 \mathrm{MW}$ \\
DC bus voltage $V_{d c}$ & $5.6 \mathrm{kV} \mathrm{DC}$ \\
* Rated primary side voltage $V_{p}$ & $3.3 \mathrm{kV} \mathrm{rms}$ \\
Rated line-to-line grid voltage $V_{g}$ & $20 \mathrm{kV} \mathrm{rms}$ \\
Rated load current $I_{\text {load }}$ & $1.75 \mathrm{kA} \mathrm{rms}$ \\
Carrier frequency $f_{c}$ & $800 \mathrm{~Hz}$ \\
Filter inductance $L_{f}$ & $1.14 \mathrm{mH}(0.3$ p.u. $)$ \\
\hline * Line-to-line voltage in the primary windings of transformer.
\end{tabular}

Three power switching device solutions using IGCT press-pack, IGBT press-pack and IGBT module for the given $10 \mathrm{MW} 3 \mathrm{~L}-\mathrm{NPC}$ wind power converter are listed in Table 3, where the device ratings, configurations, total device numbers and used device models are indicated, respectively [21,22]; the maximum allowable junction temperature for all of the given power devices is $125{ }^{\circ} \mathrm{C}$. It is noted that in order to justify and facilitate the comparison, each device solution is designed to handle the same load current up to $3.6 \mathrm{kA}$, therefore two $1.8 \mathrm{kA}$ IGBT press-packs and three $1.2 \mathrm{kA}$ IGBT modules have to be paralleled due to the limits of maximum available current rating for the corresponding power switching devices. The load current in each of the parallel device is assumed to be equally distributed. It is worth mentioning that the paralleling of power switching devices may change the 
loading profile significantly and has a strong impact on the loss, thermal, cost and power density performances of the converter. In this paper only the least paralleling number is considered for each of the power device solutions.

Table 3. Three power switching device solutions for 10 MW 3L-NPC converter.

\begin{tabular}{cccc}
\hline Solutions & Main Switch (each) & Clamping Diode (each) & Device Numbers \\
\hline IGCT Presspack & $\begin{array}{c}1 \times \text { IGCT }(3.6 \mathrm{kA} / 4.5 \mathrm{kV}) \\
1 \times \text { Diode }(3.6 \mathrm{kA} / 4.5 \mathrm{kV})\end{array}$ & $1 \times(3.6 \mathrm{kA} / 4.5 \mathrm{kV})$ Diode & 30 \\
IGBT Presspack & $\begin{array}{c}\text { I IGBT }(1.8 \mathrm{kA} / 4.5 \mathrm{kV}) \\
\text { Integrated Diode }\end{array}$ & $2 \times(1.8 \mathrm{kA} / 4.5 \mathrm{kV})$ Diode & 36 \\
IGBT Module & $\begin{array}{c}3 \times \text { IGBT }(1.2 \mathrm{kA} / 4.5 \mathrm{kV}) \\
\text { Integrated Diode }\end{array}$ & $3 \times(1.2 \mathrm{kA} / 4.5 \mathrm{kV})$ Diode & 54 \\
\hline
\end{tabular}

IGCT presspack: ABB 40L4511 with recommended freewheeling diode 10H4503; IGBT presspack: Westcode T1800GB45A with integrated freewheeling diode; IGBT Module: ABB 1200G450350 with integrated freewheeling diode.

As can be seen in Table 3, in order to achieve $10 \mathrm{MW}$ power conversion, the power semiconductors needed for the three device solutions are quite different: the IGBT module solution consumes up to $80 \%$ more device numbers than the other two press-pack solutions. This is mainly because of the maximum current rating limits for a single IGBT module. When taking into account the extra auxiliary parts like drives, fans, heat sink, wires, etc., the IGBT module solution may result in much lower power density and higher component counts, which may not be preferable in the wind power application.

\section{Thermal Related Characteristics of Different Power Switching Devices}

The junction temperature of the power switching devices is decided by the losses during switching and conducting, as well as the thermal impedance from junction to ambient [23-25]. Therefore, the characteristics related to the power loss and thermal impedance of power switching devices in Table 3 will be evaluated first.

\subsection{Switching Loss}

The switching loss of the switch (i.e., IGBT or IGCT) is generated when it is turning on and turning off ( $E_{\text {on }}$ and $E_{\text {off }}$ ), while the majority switching loss of the diode is generated when it is turning off $\left(E_{r r}\right)$ [24]. As an indicator for the switching loss characteristic, the consumed energy during the switching process (in the unit of Joule) with relation to the current flowing in the switch $\left(I_{c}\right)$ or diode $\left(I_{F}\right)$ can be derived from the datasheets of manufacturers.

The switching loss profiles of IGCT/IGBT $\left(E_{o n}+E_{\text {off }}\right)$ and diode $\left(E_{r r}\right)$ for the designed power device solutions are compared in Figure 3(a,b), respectively. It is noted that, in order to unify and compare solutions with different numbers of parallel devices, the vertical axis in Figure 3 represents the switching loss for only one switch/diode in the parallel device solutions, and the horizontal axis is normalized by the load current $I_{\text {load }}$ of the $3 \mathrm{~L}-\mathrm{NPC}$ converter rather than current flowing in the devices $\left(I_{c}\right.$ or $\left.I_{F}\right)$. 
Figure 3. Normalized switching loss profiles for different power devices (recommended test conditions, $125^{\circ} \mathrm{C}$ ). (a) Switching loss on IGCT/IGBT $E_{o n}+E_{o f f}$; (b) Switching loss on diode $E_{r r}$.

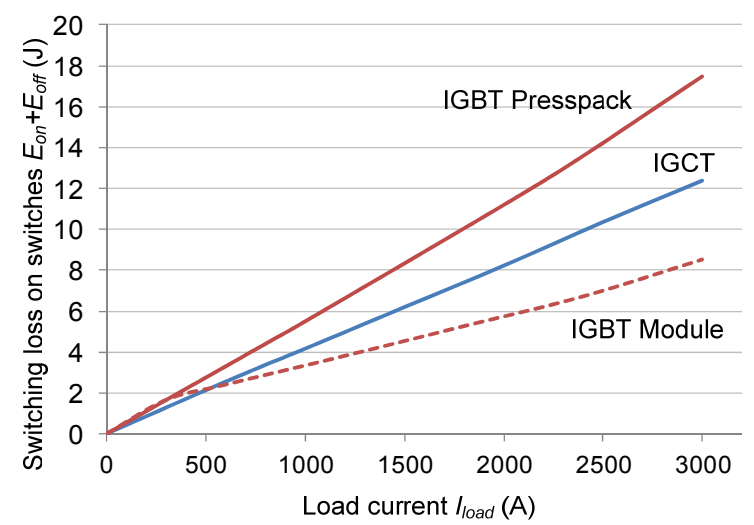

(a)

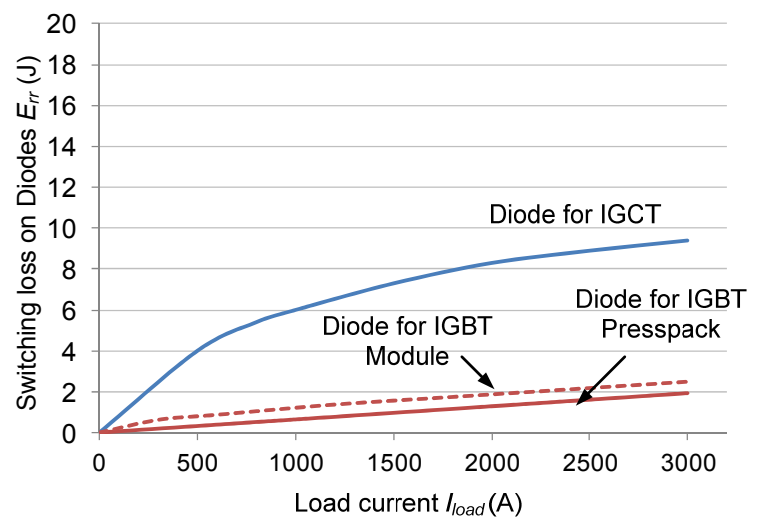

(b)

It can be seen that for the switches (i.e., IGCT or IGBT), the IGBT press-pack has a larger total switching loss $E_{\text {on }}+E_{\text {off }}$ compared to the IGCT press-pack and IGBT module. As for the freewheeling diodes, the IGCT solution shows significantly larger $E_{r r}$ compared to the other two IGBT solutions based on press-pack and module packaging technology. This may be because the clamping circuit normally used for the IGCT will significantly slow down the rising time of the load current during the turning on process, and thereby result in very large reverse recovery charge $Q_{r r}$ on the freewheeling diodes. As for the IGBT module, it shows the lowest overall switching loss either in the switches or in the freewheeling diodes.

When investigating the $E_{\text {on }}$ and $E_{\text {off }}$ on switch separately, as shown in Figure 4, it can be found that the large switching loss of IGBT press-pack comes from the larger turn on loss $E_{\text {on }}$. Due to the use of the clamping circuit, IGCT can achieve smaller turn on loss $E_{o n}$, but with the cost of a larger switching loss $E_{r r}$ in the freewheeling diode, as indicated in Figure 3(b), and as can be seen from Figure 4(b) IGCT shows a large turn off loss $E_{\text {off }}$ in the switch.

Figure 4. Normalized switching loss profiles for switches (recommended test conditions, $125^{\circ} \mathrm{C}$ ). (a) Turn on switching loss $E_{\text {on }}$; (b) Turn off switching loss $E_{\text {off. }}$

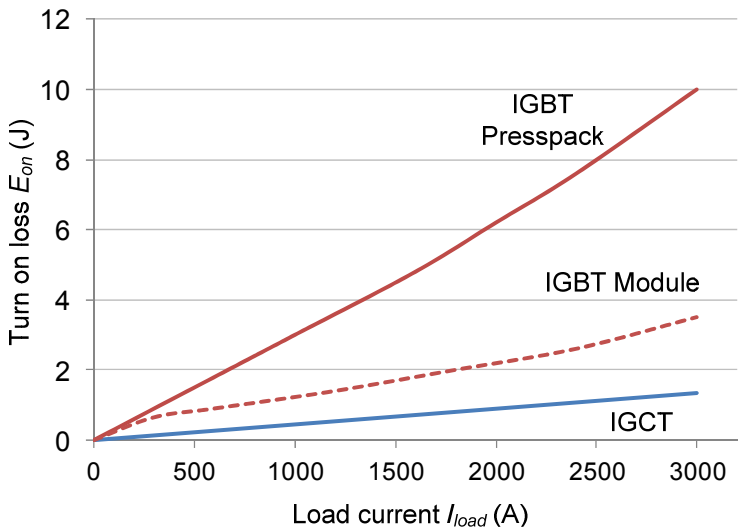

(a)

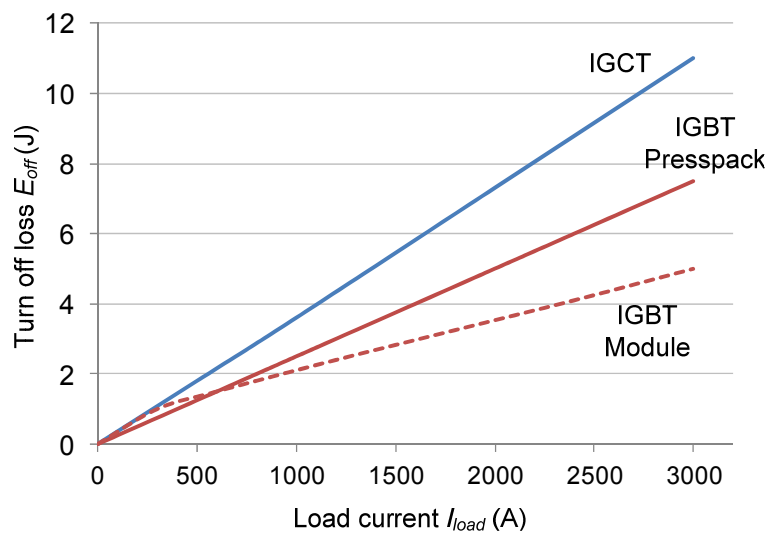

(b) 


\subsection{Conduction Voltage and Loss}

The conduction loss of the power switching devices is generated when the switch or diode is conducting the load current. As an important indicator for the conduction loss characteristic, the conduction voltage of IGCT/IGBT $v_{c e}$ or diode $v_{F}$ with relation to the current flowing in switch $\left(I_{c}\right)$ or diode $\left(I_{F}\right)$ can be also derived from the datasheets of manufacturers.

The profiles of $v_{c e}$ and $v_{F}$ for the chosen power switching devices with relation to the load current of the 3L-NPC inverter $I_{\text {load }}$ are compared in Figure 5(a,b), respectively. It can be seen that the IGCT and its freewheeling diode shows lower conduction voltage compared to the other two IGBT solutions.

Figure 5. Normalized conduction voltage for different power devices (recommended test conditions, $125^{\circ} \mathrm{C}$ ). (a) Switches and (b) Diode.

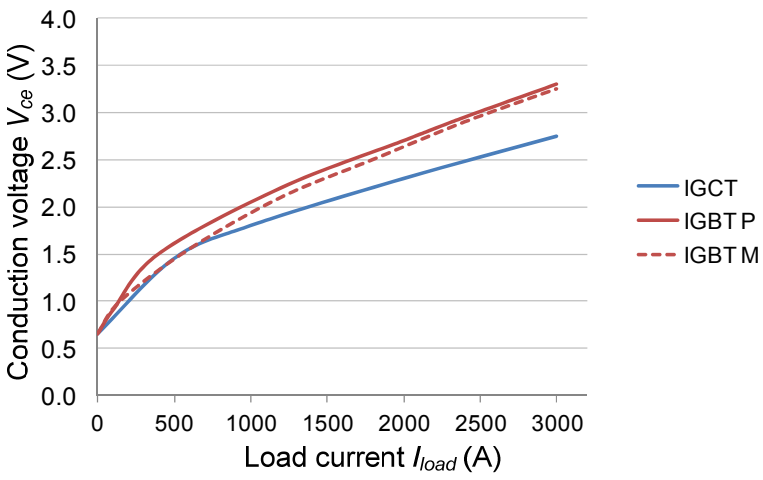

(a)

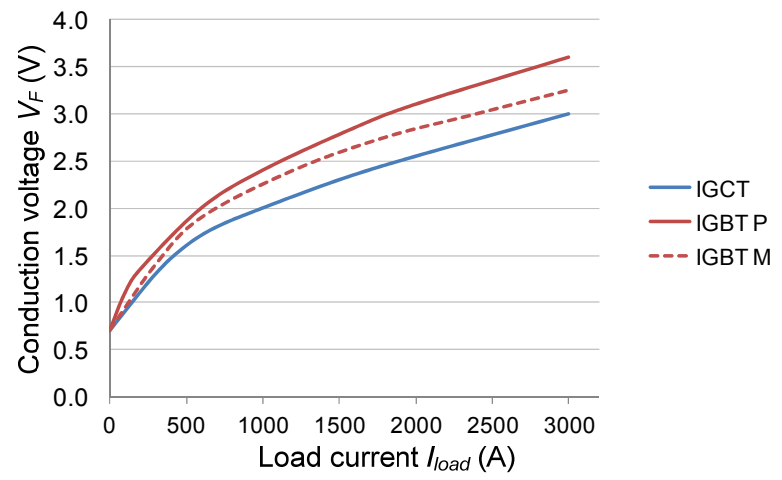

(b)

However, the conduction voltage does not directly reflect the conduction loss performance because the conduction loss is generated by both conduction voltage and current flowing in devices [26]. In order to better compare the conduction loss characteristics among different device solutions, a series of new profiles are plotted in Figure 6, where the vertical axis is changed to $V_{c e} \times I_{c}$ for switches and $V_{F} \times I_{F}$ for diodes. These profiles contain the information of both conduction voltage and switching current, and thus can directly reflect the conduction loss level of different device solutions. It is noted that the conduction loss characteristics are only for one single device in parallel device solutions.

Figure 6. Normalized conduction loss profiles for different power devices (recommended test conditions, $125^{\circ} \mathrm{C}$ ). (a) Switches and (b) Diode.

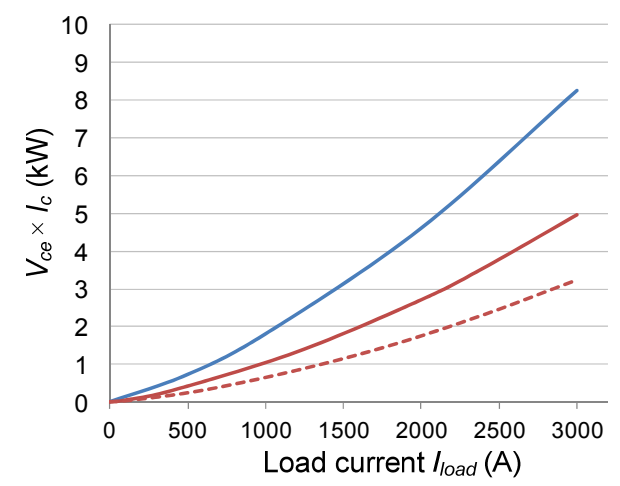

(a)

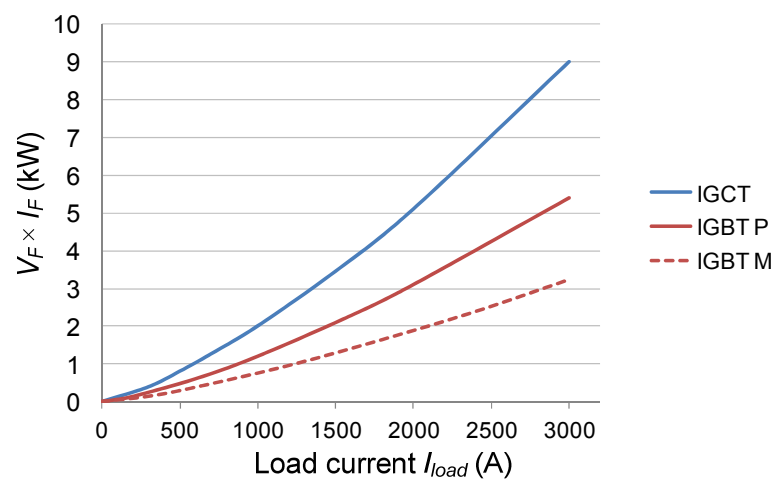

(b) 
As can be seen in Figure 6, although the IGCT solution has the lowest conduction voltage level, it shows the largest conduction loss profile for each device because of much larger current flowing in each device (the current is three times of that in each IGBT module and twice that in each IGBT press-pack, as indicated in Table 3). The IGBT module solution again shows overall lower conduction loss level in each switching device either in the switch or in the diode.

\subsection{Thermal Resistance}

The thermal resistance is another important characteristic which can determine the thermal performances of power switching devices [23]. The thermal resistance from junction to heat sink of each device solution is shown in Figure 7, where the switches and diodes are indicated respectively.

Figure 7. Thermal resistance from junction to heat sink for different power devices. $R_{t h(C H)}$ and $R_{t h(J C)}$ represent the thermal resistance from junction to case and case to heat sink, respectively.

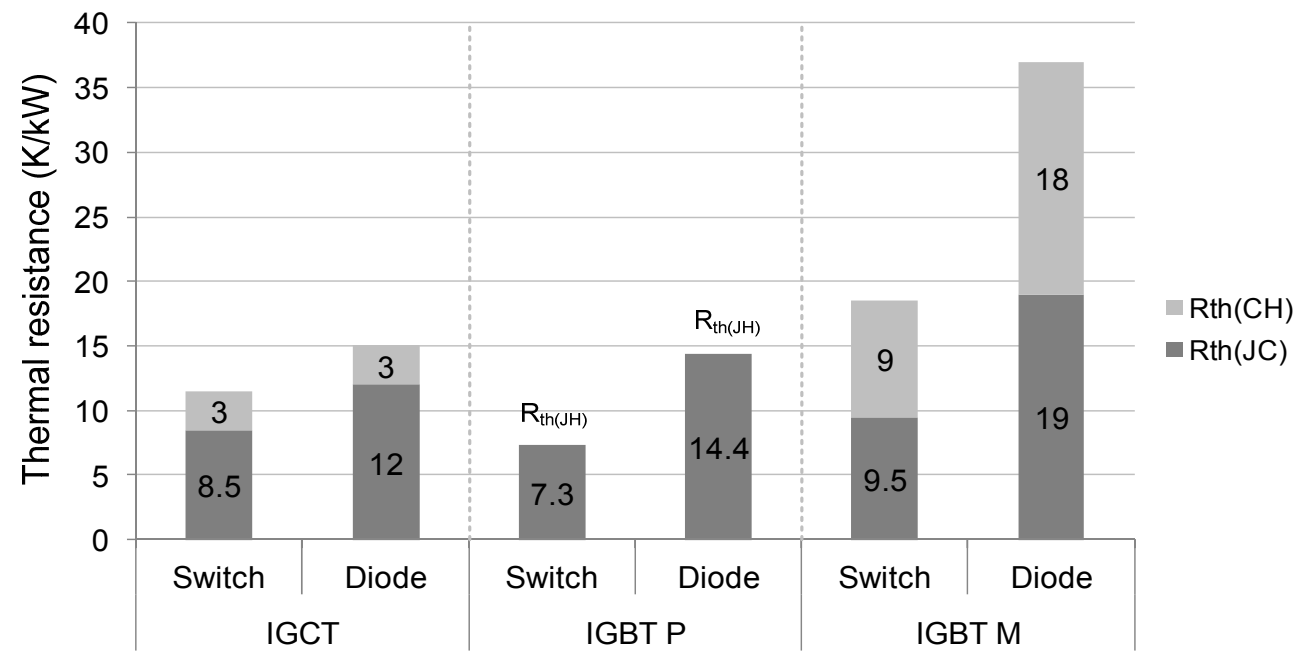

It can be seen in Figure 7 that the thermal resistance of the power switching device is closely related to the packaging technology: the press-pack devices IGCT and IGBT have significantly smaller thermal resistance both in the switches and in the freewheeling diodes than the module packaging device "IGBT M". The freewheeling diodes in all three device solutions have significantly larger thermal resistance than the corresponding IGBT or IGCT. It is noted that the major thermal resistance difference between the press-pack and module packaging devices comes from the thermal resistance outside the devices, i.e., from case to heat $\operatorname{sink} R_{t h(\mathrm{CH})}$, which is much larger for the IGBT module.

\section{Thermal Analysis of Different Device Solutions}

The thermal models for a single switch and clamping diode are indicated in Figure 8 [21-23] in which the thermal impedance from junction to case $Z_{(j-c)}$ is modeled as a multi-layer Foster RC network. Each of the thermal parameters can be found from the manufacturer datasheets, where the thermal resistance $R_{t h}$ will decide the steady state mean value of the junction temperature, and the thermal capacitance (with time constant $\tau$ ) will decide the dynamic change or fluctuation of the junction temperature. 
Figure 8. Thermal model for the analysis and simulation of 3L-NPC converter.

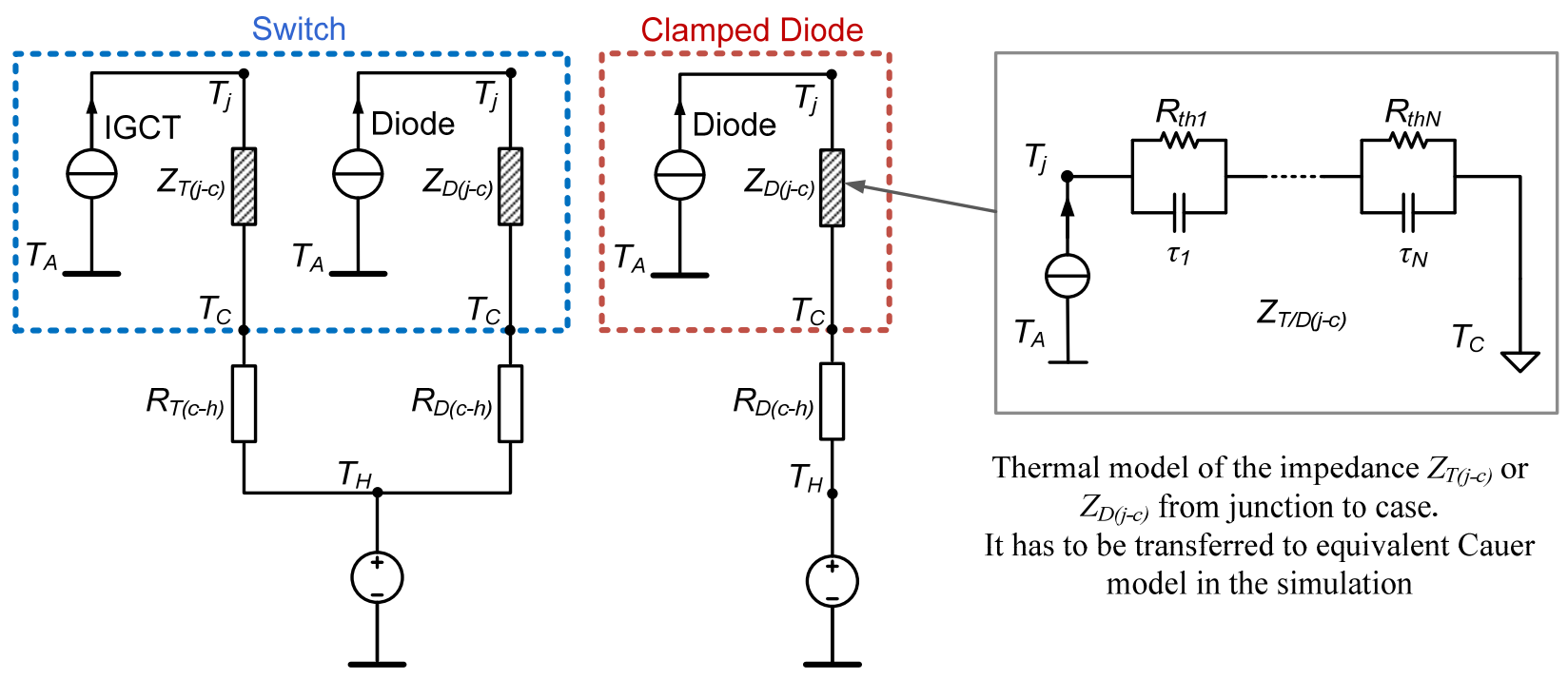

Note: $T_{j}$ : junction temperature, $T_{C}$ : case temperature, $T_{H}$ : heat sink temperature, $T_{A}$ : ambient temperature; $Z_{(j-c)}$ : thermal impedance from junction to case, $Z_{(c-h)}$ : thermal impedance from case to heat sink.

It is noted that normally the IGBT manufacturer will only provide thermal parameters inside IGBT modules with Foster RC network. In order to establish the complete thermal models from junction to the ambient, the thermal impedance of $Z_{T / D(j-c)}$ has to be transferred to the equivalent Cauer RC network to facilitate the thermal impedance extension outside IGBT modules [27]. Because the temperature of the heat sink $T_{H}$ is normally much lower and more stable compared to the junction temperature $T_{j}$ in a properly designed converter system, the heat sink temperature is considered as a constant value at $60{ }^{\circ} \mathrm{C}$ in this paper. However, the heat sink temperature may strongly depend on the operation site and the design of the heat sink system.

After the parameters for the converter as well as the loss and thermal models for the power switching devices are settled, some important operation modes of the 3L-NPC converter can be simulated. The simulations are carried out based on PLECS blockset in Simulink [27], and the simulation parameters are consistent with the ones in Tables 2 and 3; the main focus will be on the grid connected inverter.

\subsection{Normal operation}

The thermal cycling performance of the $3 \mathrm{~L}-\mathrm{NPC}$ wind power inverter when the wind turbine is running at rated wind speed $12 \mathrm{~m} / \mathrm{s}$ and rated grid voltage will first be analyzed. Figure 9 shows the converter output voltage pulses, phase current and grid voltage under rated and normal conditions of the wind turbines. It can be seen that the load current is in phase with the grid voltage, i.e., power factor $P F=1$. 
Figure 9. Simulation outputs of 3L-NPC inverter under rated normal operation (output voltage pulses-green, grid voltage-blue, phase current-red, $V_{g}=1$ p.u., $P F=1, v_{w}=12 \mathrm{~m} / \mathrm{s}$, DC bus voltage $V_{D C}=1$ p.u.).

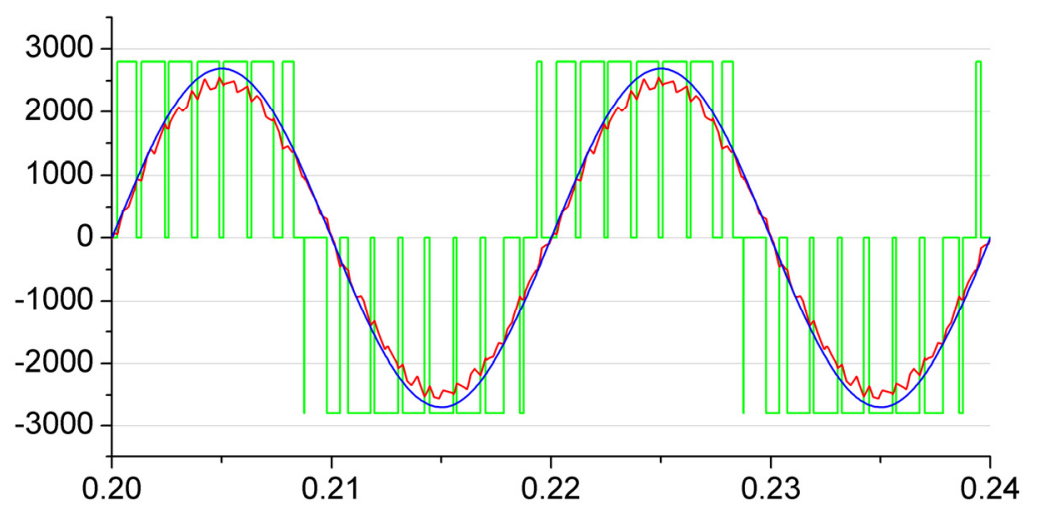

\subsubsection{Loss Distribution}

The loss calculation method is based on the same idea as in [26,28], which is a commonly accepted method for the loss evaluation of power semiconductor devices. It is noted that the switching loss profile of the chosen switching devices only has the test condition at $125{ }^{\circ} \mathrm{C}$ on the datasheet; the loss models in this paper are therefore considered temperature independent during the simulation. However, if the device characteristics under other temperatures are provided, the loss model with junction temperature dependence can be established and simulated by iteration in the simulation software.

The loss distribution of the 3L-NPC converter with different device solutions under the normal rated condition is shown in Figure 10, where only one single device is indicated if parallel power device solutions are applied.

Figure 10. Loss distribution for different power switching devices under normal operation of Figure 9 ( $L_{c o n}$ means conduction loss-red, $L_{s w}$ means switching loss-blue).

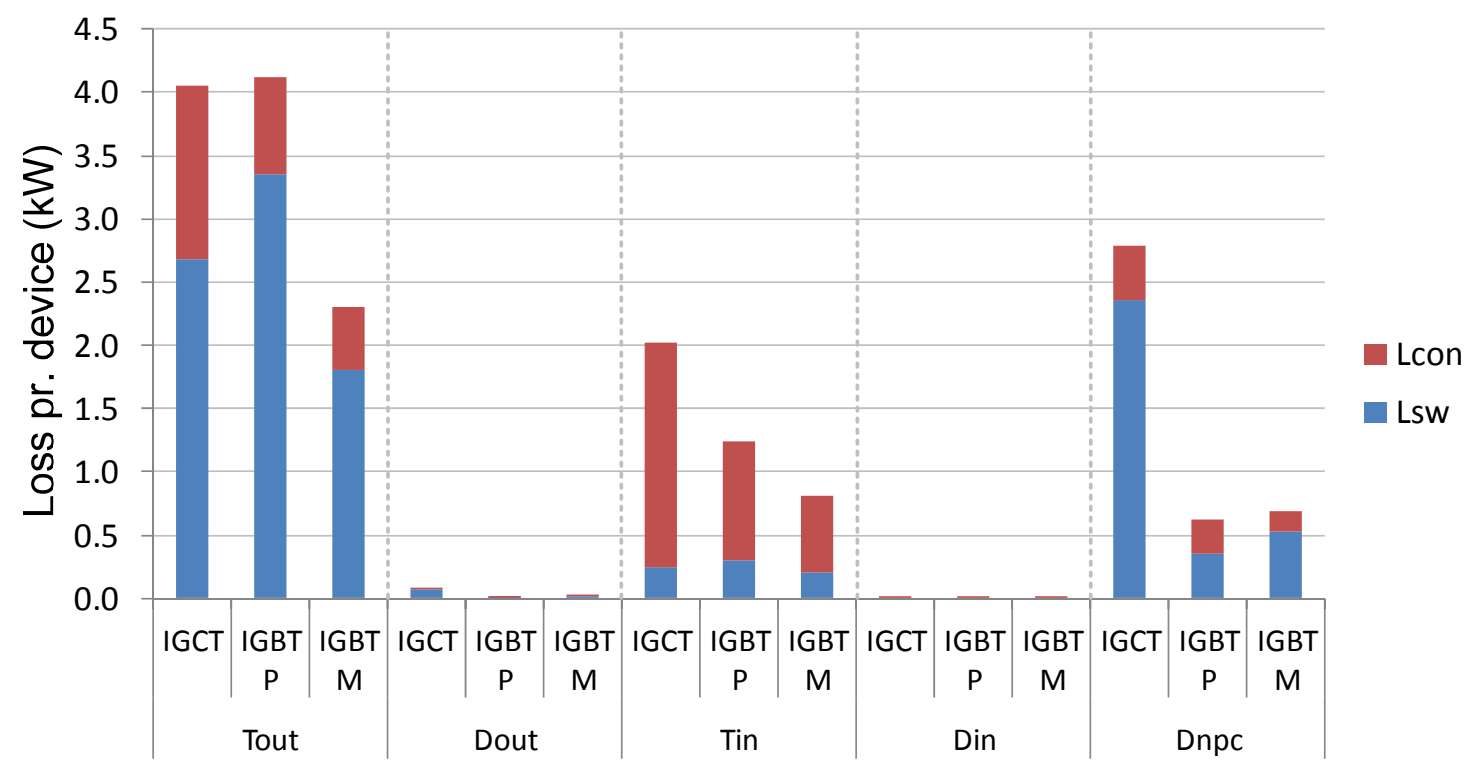


As it can be seen from Figure 10, the major losses for all the device solutions are consumed by the outer switches $T_{\text {out }}$, inner switches $T_{\text {in }}$ and the clamping diodes $D_{\text {npc }}$ under normal operation of the wind power converter. The IGCT solution shows significantly larger loss in $\mathrm{D}_{\mathrm{npc}}$ due to larger switching loss; on the other hand the IGBT module solution shows significantly lower overall loss level especially in $\mathrm{T}_{\text {out }}$.

\subsubsection{Thermal Performances}

With the thermal model in Figure 8 and loss information in Figure 10, the steady state cyclic junction temperature for the switching devices in the given 3L-NPC inverter can be also simulated, as shown in Figure 11, where only one single device is indicated if the parallel power device solutions are applied. It is noted that the short time overloading is possible because all of the junction temperature is below the upper limit $125^{\circ} \mathrm{C}$; in the real life the temperature fluctuation on the heat sink should also be added. It can be seen that the thermal distributions with different device solutions are quite different.

Figure 11. Thermal cycling of the $3 \mathrm{~L}-\mathrm{NPC}$ inverter with different switching device solutions (normal operation condition in Figure 9). (a) IGCT presspack solution; (b) IGBT presspack solution and (c) IGBT module solution.

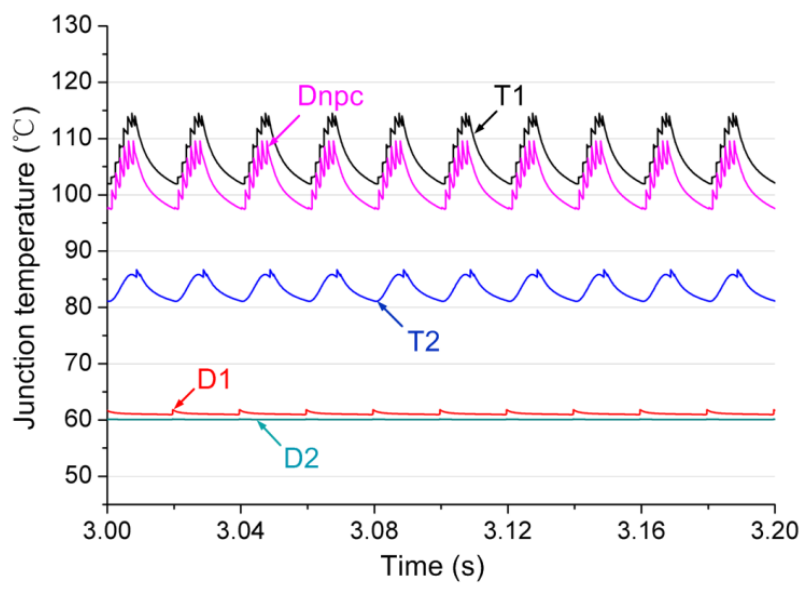

(a)

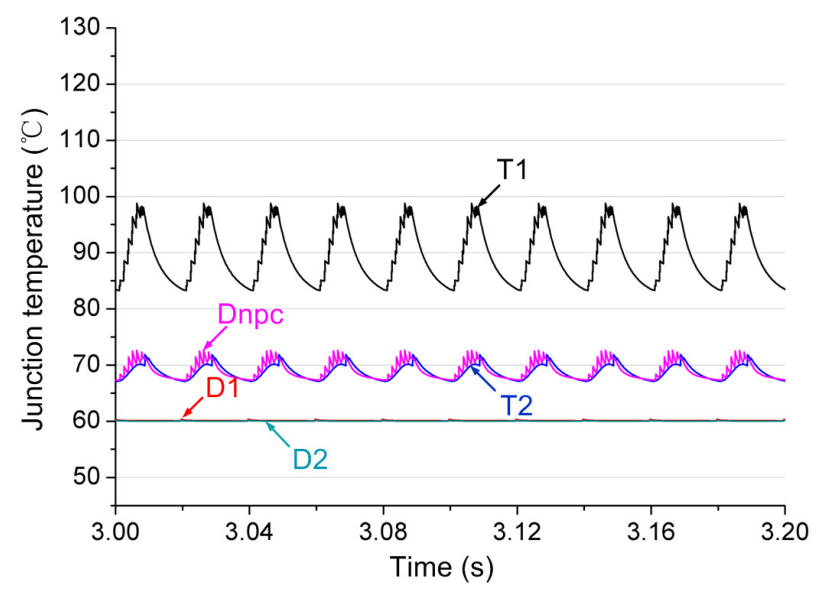

(b)

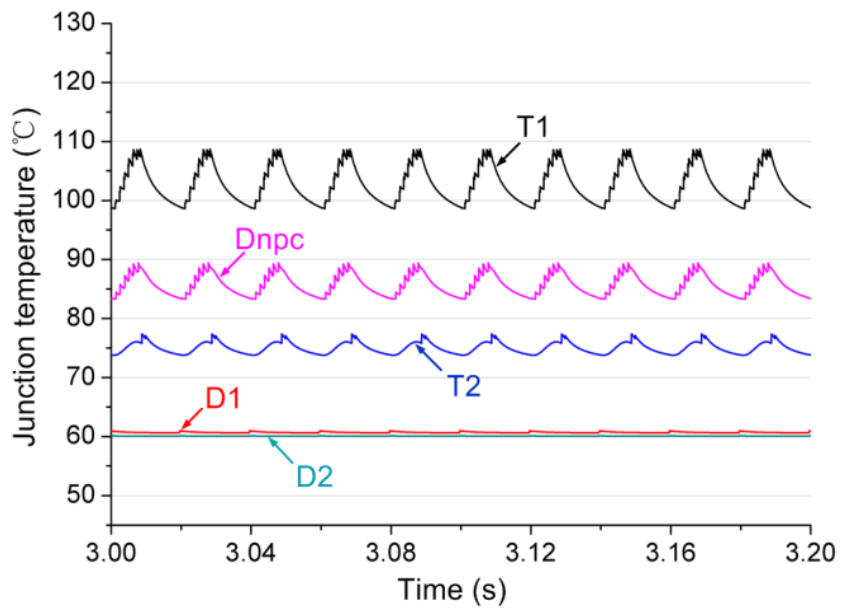

(c) 
The junction temperature mean value $T_{j m}$ and temperature fluctuation $\Delta T_{j}$ for each of the switching devices for different device solutions in Figure 11 are summarized in Figure 12. Obviously, the IGCT solution has larger $T_{j m}$ and $\Delta T_{j}$ in almost all of the switching devices especially for the clamping diode $\mathrm{D}_{\text {npc }}$. For the IGBT press-pack solution it shows the lowest $T_{j m}$ level but a relatively higher $\Delta T_{j}$ level. The IGBT module solution does not achieve the best thermal performance with the lowest power losses because of much larger thermal resistance.

Figure 12. Thermal cycling profile of the $3 \mathrm{~L}-\mathrm{NPC}$ inverter with different switching device solutions under normal operation ( $V_{g}=1$ p.u., $P F=1, v_{w}=12 \mathrm{~m} / \mathrm{s}$ ). (a) Mean junction temperature $T_{j m}$ and (b) Junction temperature fluctuation $\Delta T_{j}$.

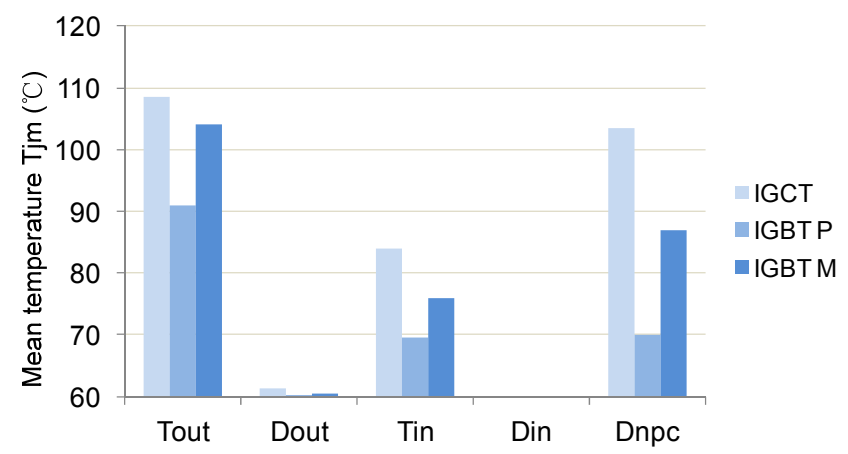

(a)

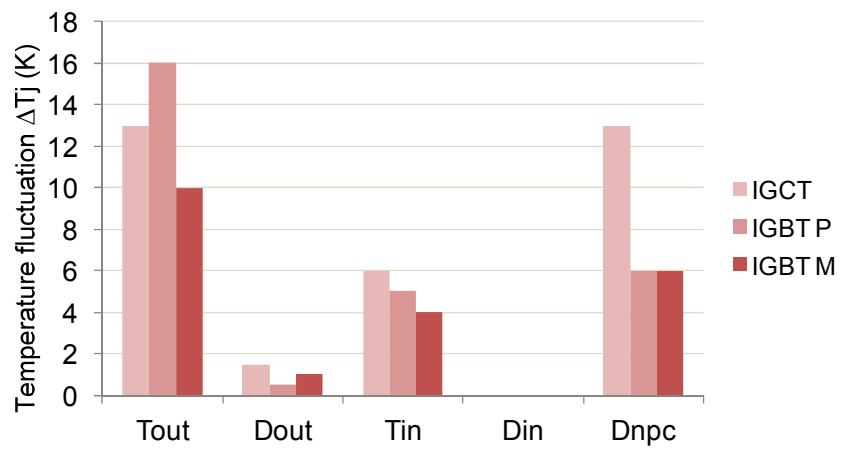

(b)

\subsection{Low-Voltage-Ride-Through Operation}

The simulation output of the 3L-NPC inverter undergoing low voltage rid through (LVRT) operation is shown in Figure 13, in which the grid voltage is set to 0.05 p.u. of the rated value as a severe voltage dip, and the converter has to provide $100 \%$ rated reactive current according to the grid codes $[29,30]$. It can be seen that the phase current lags 90 degrees to the grid phase voltage, and the inverter achieves $100 \%$ rated reactive current injection $(1.75 \mathrm{kA} \mathrm{rms})$ into the power grid.

Figure 13. Simulation outputs of 3L-NPC inverter under LVRT operation (output voltage pulses-green, grid voltage-blue, phase current-red, $V_{g}=0.05$ p.u., $100 \%$ rated reactive current, DC bus voltage VDC $=1.1$ p.u.).

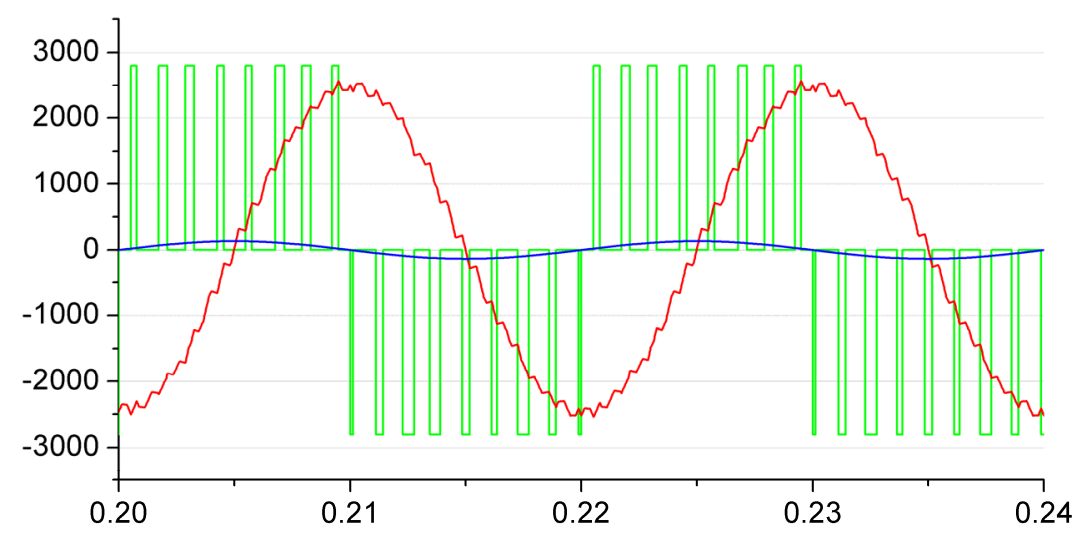




\subsubsection{Loss Distribution}

The loss distribution of the 3L-NPC inverter undergoing the given LVRT operation is shown in Figure 14, where different device solutions are indicated and compared. It can be seen that the loss distribution is quite different from the one undergoing normal operation in Figure 10; $T_{\text {in }}$ has the highest power loss for all of the device solutions. The IGCT solution again shows significantly larger loss in $\mathrm{D}_{\mathrm{npc}}$, while the IGBT module solution has the lowest power loss level.

Figure 14. Loss distribution for different power switching device solutions under LVRT operation of Figure 13 (Lcon means conduction loss-red, Lsw means switching loss-blue).

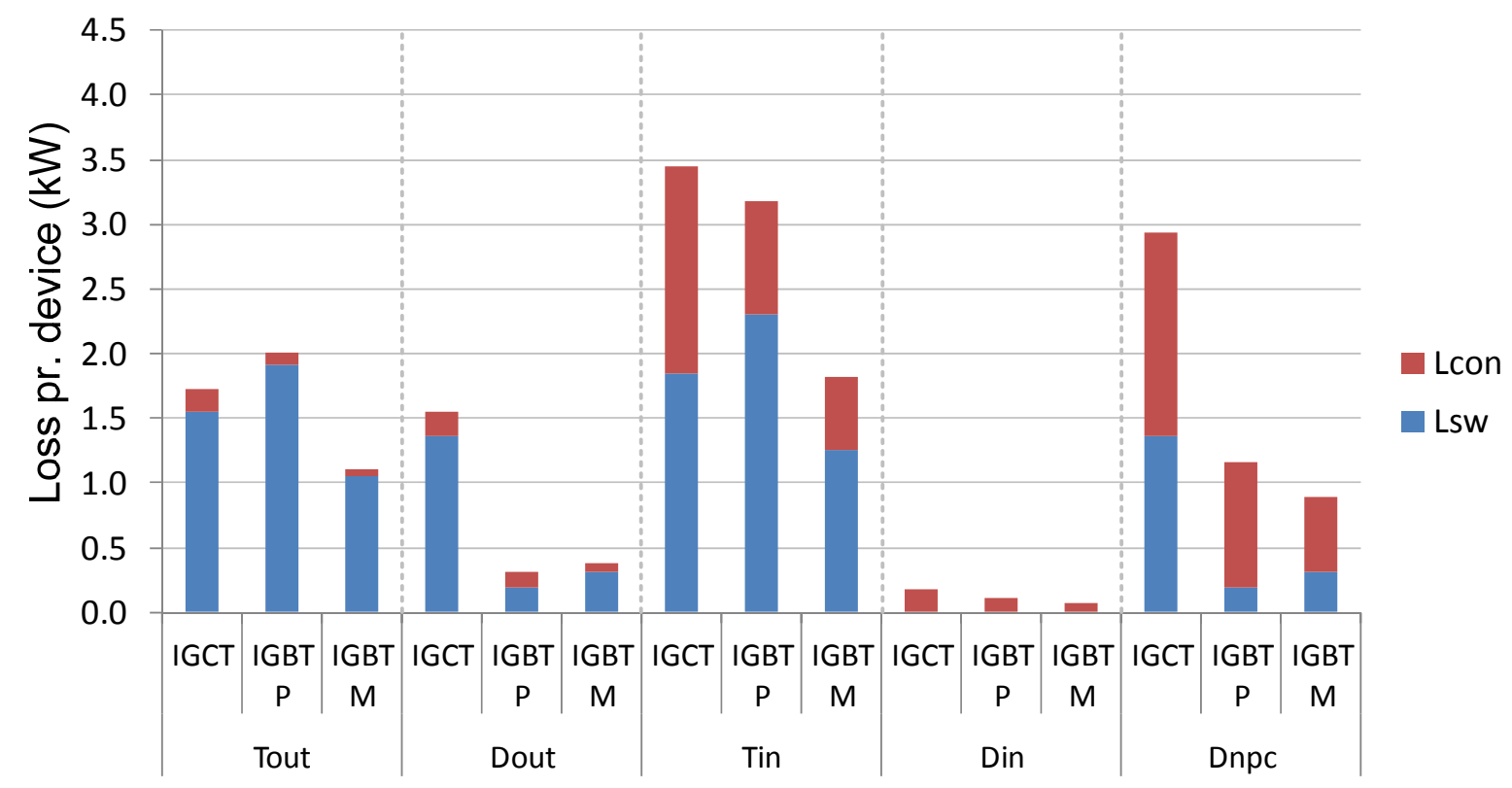

\subsubsection{Thermal Performances}

The junction temperature for each of the power switching devices in the given 3L-NPC inverter can be also simulated under LVRT operation, as shown in Figure 15, where only one single device is indicated if parallel power device solutions are applied. It can be seen that the thermal distributions with different device solutions are still quite different from each other under LVRT operation of wind turbines.

The junction temperature mean value $T_{j m}$ and temperature fluctuation $\Delta T_{j}$ for each of the switching device for different device solutions in Figure 15 are summarized in Figure 16. It can again be seen that the IGCT solution has larger $T_{j m}$ and $\Delta T_{j}$ in almost all of the switching devices especially for the clamping diode $\mathrm{D}_{\text {npc }}$. The IGBT press-pack solution shows the lower $T_{j m}$ but higher $\Delta T_{j}$ compared to the other two device solutions. 
Figure 15. Thermal cycling of the $3 \mathrm{~L}-\mathrm{NPC}$ inverter with different switching device solutions during Low-Voltage-Ride-Through operation condition in Figure 13. (a) IGCT presspack solution; (b) IGBT presspack solution and (c) IGBT module solution.

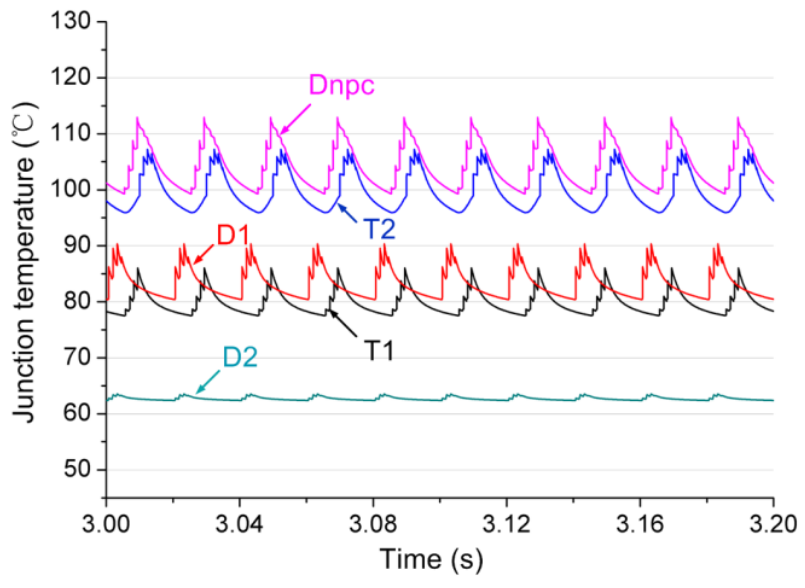

(a)

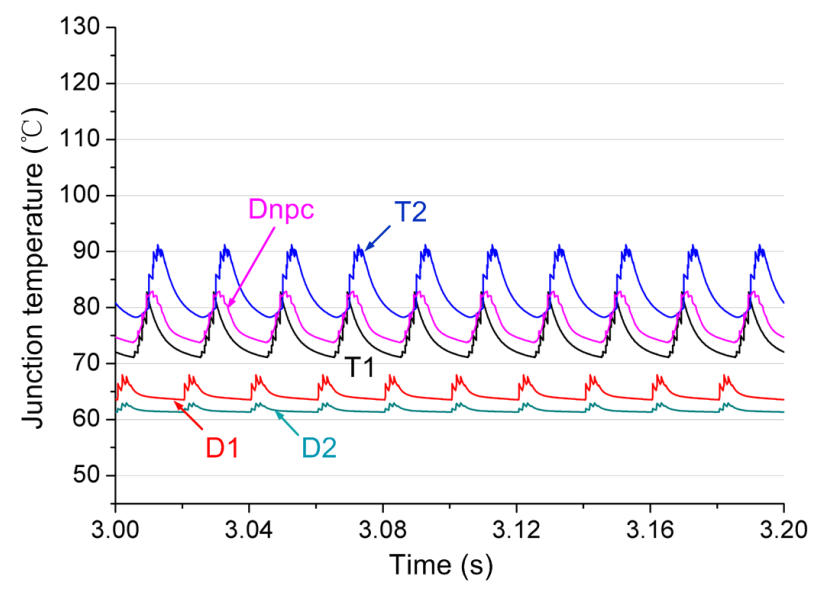

(b)

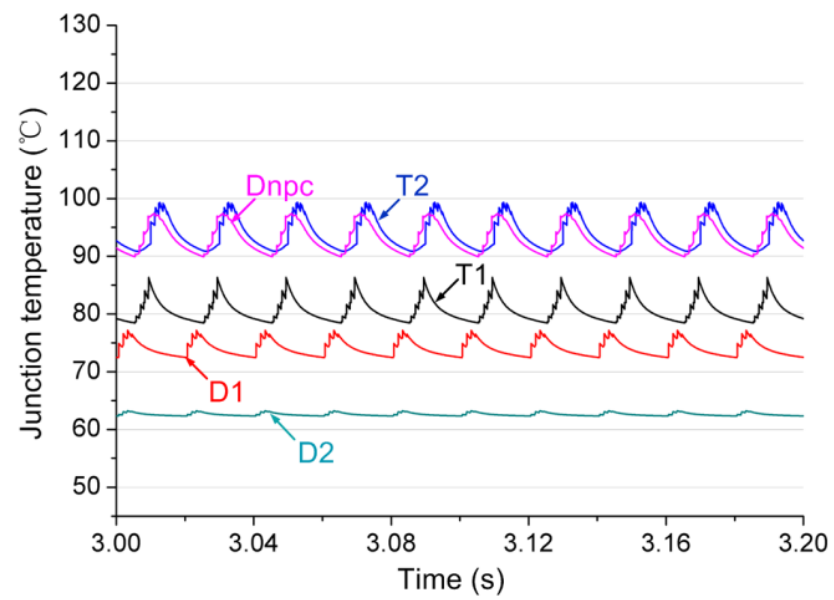

(c)

Figure 16. Thermal cycling profile of the 3L-NPC inverter with different switching device solutions under Low-Voltage-Ride-Through operation $\left(V_{g}=0.05\right.$ p.u., $100 \%$ rated reactive current). (a) Mean junction temperature $T_{j m}$ and (b) Junction temperature fluctuation $\Delta T_{j}$.

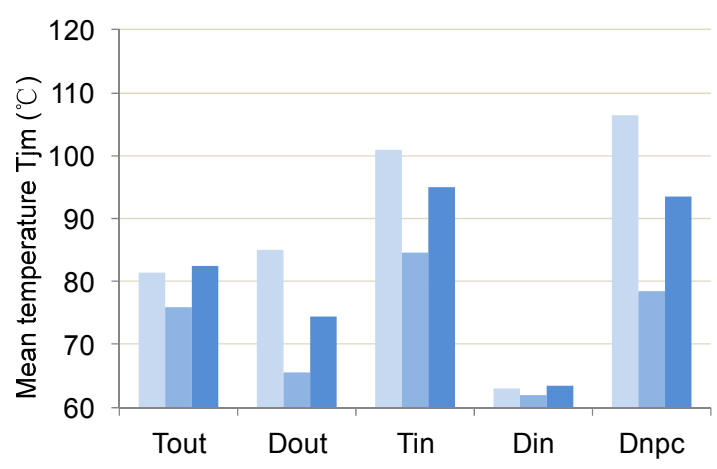

(a)

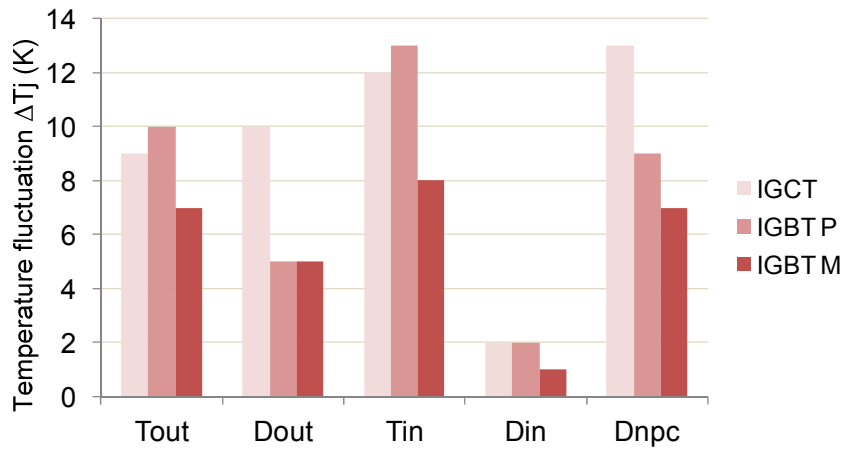

(b) 


\subsection{Wind Gust Operation}

The wind gust operation of wind turbines may impose power switching devices with large thermal cycling amplitude and longer time disturbances compared to the LVRT and normal operation modes. According to the one-year return period wind gust definition by IEC standards [31], a wind gust condition for a case study is indicated in Figure 17, where the wind speed is set from $10 \mathrm{~m} / \mathrm{s}$ dropping to $8 \mathrm{~m} / \mathrm{s}$ and rising to $16 \mathrm{~m} / \mathrm{s}$; the reverse fashion is then continued. The active current reference of the converter is accordingly changed with the wind speed referring to the wind turbine model in [20].

Figure 17. Wind speed and current references of grid side 3L-NPC inverter in a defined wind gust.

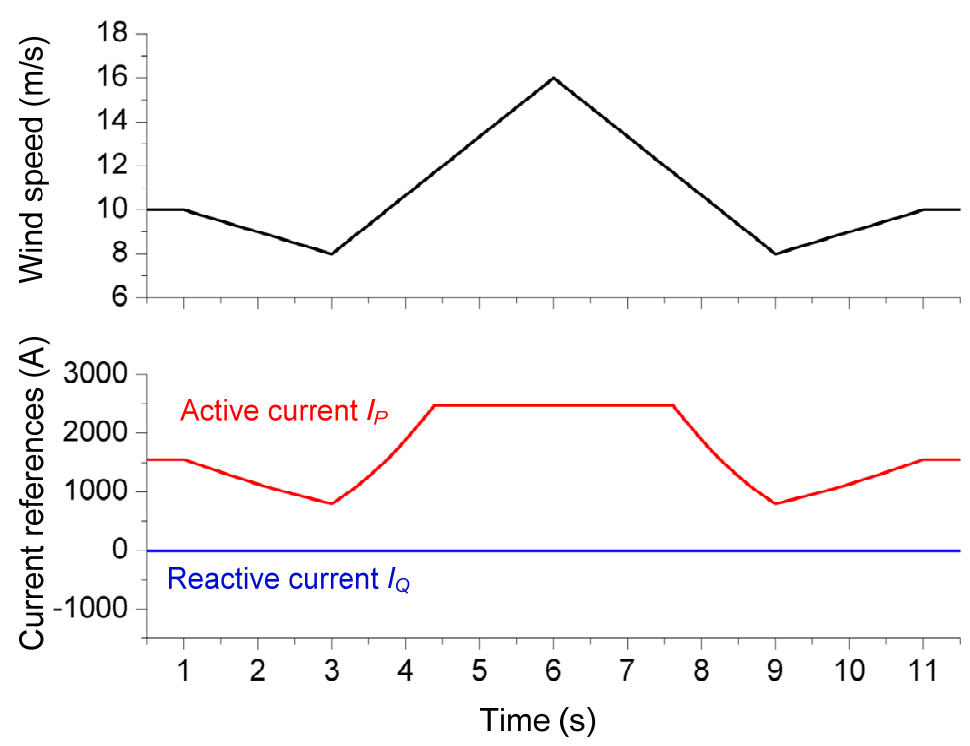

The junction temperature distributions of the target 3L-NPC inverter during the given wind gust operation condition are indicated in Figure 18. It is obvious that three device solutions show significant differences in the most stressed devices, temperature fluctuation amplitude, and thermal distribution.

The maximum junction temperature fluctuation amplitudes with different device solutions are summarized in Figure 18(d). It can be seen that the temperature in $\mathrm{T}_{\text {out }}$ is the most fluctuated device in all of the proposed solutions, and the IGCT solution shows more temperature fluctuation amplitude in $\mathrm{T}_{\text {in }}$ and $\mathrm{D}_{\mathrm{npc}}$ under the given wind gust defined by the IEC standards.

\subsection{Summary of Thermal Performances under Different Operation Modes}

Finally, both the most stressed and least stressed devices of the 3L-NPC inverter with different device solutions are summarized in Table 4 and Table 5, respectively, where the defined three operation modes of wind turbines are included.

It is interesting to see that for all of the power switching device solutions, the outer switches $\mathrm{T}_{\text {out }}$, clamping diodes $D_{\text {npc }}$ and inner switch $T_{\text {in }}$ are likely to become the most stressed devices under various operations of wind turbines, while the outer diode $\mathrm{D}_{\text {out }}$ and inner diode $\mathrm{D}_{\text {in }}$ are barely used with all of the device solutions under various operation modes. This information may be used to guide the design and selection of power device for 3L-NPC wind power converter. 
Figure 18. Thermal cycling of the $3 \mathrm{~L}-\mathrm{NPC}$ inverter with different switching device solutions (wind gust operation in Figure 13). (a) IGCT presspack solution; (b) IGBT presspack solution; (c) IGBT module solution and (d) Junction temperature fluctuation $\Delta T_{j}$.

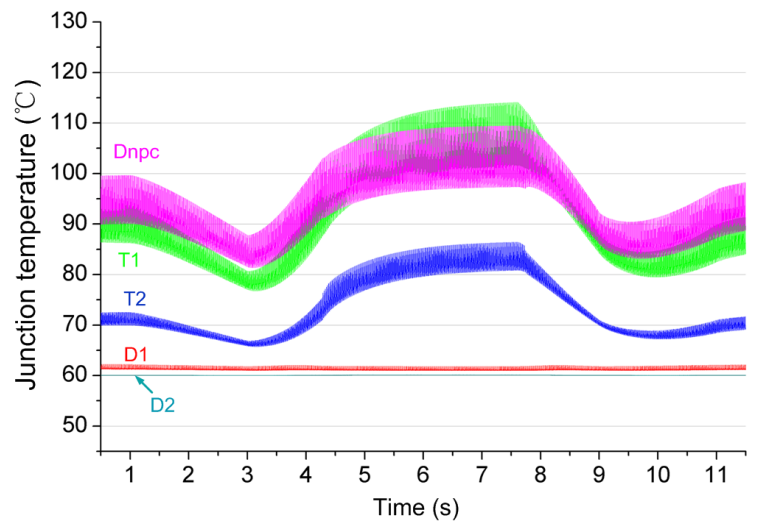

(a)

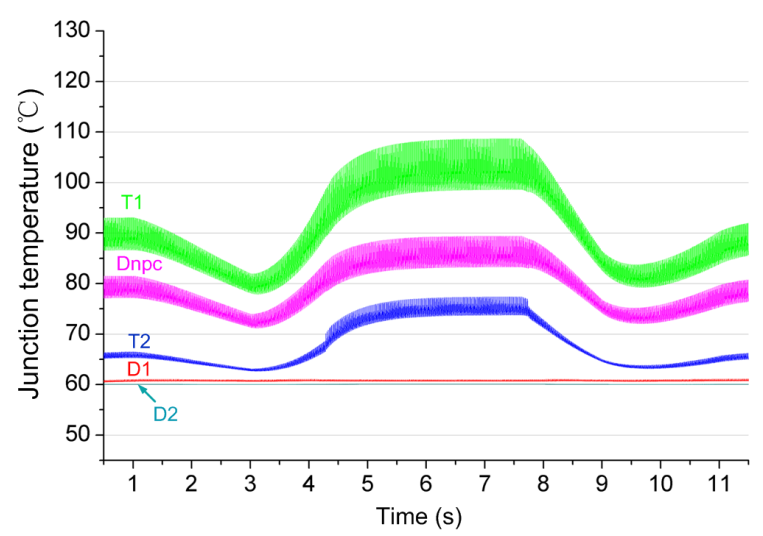

(c)

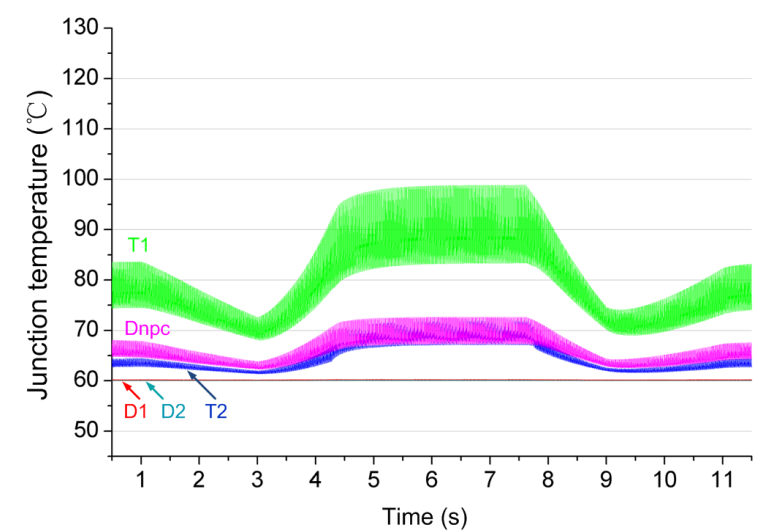

(b)

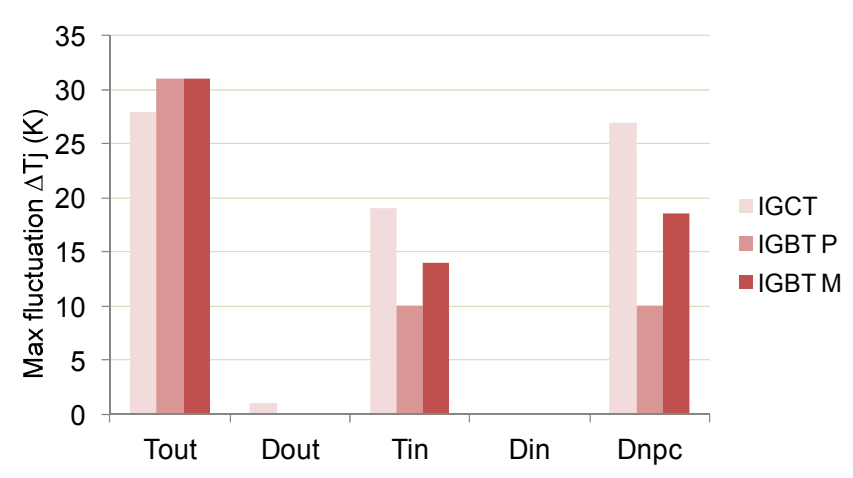

(d)

Table 4. Most stressed devices for different power device solutions.

\begin{tabular}{lccc}
\hline \multicolumn{1}{c}{ Solutions } & Normal & LVRT & Wind Gust \\
\hline IGCT Presspack & $\mathrm{T}_{\text {out }} \& \mathrm{D}_{\text {npc }}$ & $\mathrm{D}_{\text {npc }} \& \mathrm{~T}_{\mathrm{in}}$ & $\mathrm{D}_{\text {npc }} \& \mathrm{~T}_{\text {out }}$ \\
IGBT Presspack & $\mathrm{T}_{\text {out }}$ & $\mathrm{T}_{\text {in }}$ & $\mathrm{T}_{\text {out }}$ \\
IGBT Module & $\mathrm{T}_{\text {out }}$ & $\mathrm{D}_{\text {npc }} \& \mathrm{~T}_{\text {in }}$ & $\mathrm{T}_{\text {out }}$ \\
\hline
\end{tabular}

Table 5. Least stressed devices for different power device solutions.

\begin{tabular}{lccc}
\hline \multicolumn{1}{c}{ Solutions } & Normal & LVRT & Wind Gust \\
\hline IGCT Presspack & $\mathrm{D}_{\text {out }} \& \mathrm{D}_{\text {in }}$ & $\mathrm{D}_{\text {in }}$ & $\mathrm{D}_{\text {out }} \& \mathrm{D}_{\text {in }}$ \\
IGBT Presspack & $\mathrm{D}_{\text {out }} \& \mathrm{D}_{\text {in }}$ & $\mathrm{D}_{\text {in }}$ & $\mathrm{D}_{\text {out }} \& \mathrm{D}_{\text {in }}$ \\
IGBT Module & $\mathrm{D}_{\text {out }} \& \mathrm{D}_{\text {in }}$ & $\mathrm{D}_{\text {in }}$ & $\mathrm{D}_{\text {out }} \& \mathrm{D}_{\text {in }}$ \\
\hline
\end{tabular}

\section{Conclusions}

The thermal performance of power switching devices is important for modern wind power converter systems. It is found that the thermal related characteristics of the three dominant power switching devices in wind power application are quite different. 
For all of the power switching device solutions in the $3 \mathrm{~L}-\mathrm{NPC}$ grid side inverter, the outer switches $T_{\text {out }}$, clamping diodes $D_{\text {npc }}$ and inner switch $T_{\text {in }}$ are likely to become the most stressed devices under various important operation modes of the wind turbines and therefore they are critical components for the $3 \mathrm{~L}-\mathrm{NPC}$ wind power converter. The performance of the outer freewheeling diode $\mathrm{D}_{\text {out }}$ and inner freewheeling diode $\mathrm{D}_{\text {in }}$ are less important because they are barely used.

Regarding the most stressed devices $T_{\text {out }}, T_{\text {in }}$ and $D_{\text {npc }}$, the three device solutions show quite different loading behaviors because of different power loss and thermal impedance characteristics: for the IGCT solution, the switching loss in the diode is much larger because of the normally used clamping circuit. This disadvantage may lead to much higher junction temperature in $\mathrm{D}_{\mathrm{npc}}$ in comparison with the other two IGBT solutions. The IGBT press-pack solution tends to have larger switching loss in the switch. However because of smaller thermal resistance, it shows a junction temperature level in the switches similar to the IGCT solution, but with much better thermal performance in the clamping diode. The IGBT module solution shows the best loss performances among the three device solutions, but due to much larger thermal resistance especially from case to heat sink, the junction temperature level is generally high. It is noted that the IGBT module solution may result in large component counts in a $10 \mathrm{MW}$ power conversion system, which may not be preferable in the wind power application.

Finally, it is worth mentioning that the paralleling of power switching devices may change the loading profile significantly and has a strong impact on the loss, thermal, cost and power density performances of the converter; the parallel numbers of power switching devices should thus be carefully evaluated in the design process.

\section{References}

1. European Commission Climate Action. The EU Climate and Energy Package; 2007. Available online: http://ec.europa.eu/clima/policies/package/index_en.htm (accessed on 17 July 2012).

2. Blaabjerg, F.; Chen, Z.; Kjaer, S.B. Power electronics as efficient interface in dispersed power generation systems. IEEE Trans. Power Electron. 2004, 19, 1184-1194.

3. Chen, Z.; Guerrero, J.M.; Blaabjerg, F. A review of the state of the art of power electronics for wind turbines. IEEE Trans. Power Electron. 2009, 24, 1859-1875.

4. Wind Turbines Overview; Vestas Wind Power: Aarhus, Denmark, 2011. Available online: http://www.vestas.com/ (accessed on 26 June 2012).

5. Blaabjerg, F.; Liserre, M.; Ma, K. Power electronics converters for wind turbine systems. IEEE Trans. Ind. Appl. 2012, 48, 708-719.

6. Busca, C.; Teodorescu, R.; Blaabjerg, F.; Munk-Nielsen, S.; Helle, L.; Abeyasekera, T.; Rodriguez, P. An overview of the reliability prediction related aspects of high power IGBTs in wind power applications. Microelectron. Reliab. 2011, 51, 1903-1907.

7. Jakob, R.; Keller, C.; Gollentz, B. 3-level high power converter with press pack IGBT. In Proceedings of 12th European Conference on Power Electronics and Applications (EPE 2007), Aalborg, Denmark, 2-5 September 2007; pp. 1-7. 
8. Alvarez, R.; Filsecker, F.; Bernet, S. Comparison of press-pack igbt at hard switching and clamp operation for medium voltage converters. In Proceedings of 14th European Conference on Power Electronics and Applications (EPE 2011), Birmingham, UK, 30 August-1 September 2011.

9. Kaminski, N. Load-Cycle Capability of HiPaks; ABB Application Note 5SYA 2043-01, September 2004. Avaiable online: http://www.abb.dk/product/us/9AAC910029.aspx (accessed on 17 July 2012)

10. Wintrich, A.; Nicolai, U.; Reimann, T. Semikron Application Manual, 2011; pp. 1-128. Available online: http://www.semikron.com/ (accessed on 17 July 2012)

11. Kovacevic, I.F.; Drofenik, U.; Kolar, J.W. New physical model for lifetime estimation of power modules. In Proceedings of International Power Electronics Conference (IPEC 2010), Sapporo, Japan, 27-29 October 2010; pp. 2106-2114.

12. Due, J.; Munk-Nielsen, S.; Nielsen, R. Lifetime investigation of high power IGBT modules. In Proceedings of 14th European Conference on Power Electronics and Applications (EPE 2011), Birmingham, UK, 30 August-1 September 2011.

13. Kouro, S.; Malinowski, M.; Gopakumar, K.; Pou, J.; Franquelo, L.G.; Wu, B.; Rodriguez, J.; Perez, M.A.; Leon, J.I. Recent advances and industrial applications of multilevel converters. IEEE Trans. Power Electron. 2010, 57, 2553-2580.

14. Krug, D.; Bernet, S.; Fazel, S.S.; Jalili, K.; Malinowski, M. Comparison of 2.3-kV medium-voltage multilevel converters for industrial medium-voltage drives. IEEE Trans. Ind. Electron. 2007, 54, 2979-2992.

15. Rodriguez, J.; Bernet, S.; Steimer, P.K; Lizama, I.E. A survey on neutral-point-clamped inverters. IEEE Trans. Ind. Electron. 2010, 57, 2219-2230.

16. Malinowski, M.; Stynski, S.; Kolomyjski, W.; Kazmierkowski, M.P. Control of three-level PWM converter applied to variable-speed-type turbines. IEEE Trans. Ind. Appl. 2009, 56, 69-77.

17. Alepuz, S.; Busquets-Monge, S.; Bordonau, J.; Gago, J.; Gonzalez, D.; Balcells, J. Interfacing renewable energy sources to the utility grid using a three-level inverter. IEEE Trans. Ind. Electron. 2006, 53, 1504-1511.

18. Ma, K.; Blaabjerg, F. Multilevel Converters for $10 \mathrm{MW}$ Wind Turbines. In Proceedings of 14th European Conference on Power Electronics and Applications (EPE 2011), Birmingham, UK, 30 August-1 September 2011.

19. Li, H.; Chen, Z.; Polinder, H. Optimization of multibrid permanent-magnet wind generator systems. IEEE Trans. Energy Convers. 2009, 24, 82-92.

20. Polinder, H.; van der Pijl, F.F.A.; de Vilder, G.-J.; Tavner, P.J. Comparison of direct-drive and geared generator concepts for wind turbines. IEEE Trans. Energy Convers 2006, 21, 725-733.

21. ABB Semiconductors Homepage. Available online: http://www.abb.com/semiconductors (accessed on 17 July 2012).

22. Insulated Gate Bi-polar Transistors-Capsule Types; IXYS UK Westcode Ltd.: Wiltshire, UK, 2012. Available online: http://www.westcode.com/igbt.htm (accessed on 26 June 2012).

23. Infineon Application Note: Thermal Resistance Theory and Practice; Infineon Technologies AG: Neubiberg, Germany, January 2000.

24. ABB Application Note: Applying IGBTs; ABB Schweiz AG: Zürich, Switzerland, 2007. 
25. Semikron Application Manual Section 5: Application notes for IGBt and MOSFET Modules; SEMIKRON: Zürich, Switzerland, 2011.

26. Blaabjerg, F.; Jaeger, U.; Munk-Nielsen, S.; Pedersen, J. Power losses in PWM-VSI inverter using NPT or PT IGBT devices. IEEE Trans. Power Electron. 1995, 10, 358-367.

27. User Manual of PLECS Blockset; version 3.3; Plexim GmbH: Zürich, Switzerland, 2011. Available online: http://www.plexim.com/files/plecsmanual.pdf (accessed on 26 June 2012).

28. Staudt, I. 3L NPC Topology; Semikron application note AN-11001; SEMIKRON: Zürich, Switzerland, 2012. Available online: http://www.semikron.com/skcompub/en/AN11001rev03_3L_NPC_TNPC_Topology.pdf(accessed on 26 June 2012).

29. Altin, M.; Goksu, O.; Teodorescu, R.; Rodriguez, P.; Bak-Jensen, B.; Helle, L. Overview of recent grid codes for wind power integration. In Proceedings of 12th International Conference on Optimization of Electrical and Electronic Equipment (OPTIM 2010), Brasov, Romania, 20-22 May 2010; pp. 1152-1160.

30. E.ON-Netz - Grid Code: High and Extra High Voltage; E.ON Netz GmbH: Bayreuth, Germany, 2006.

31. Wind Turbines, Part 1: Design Requirements, IEC 61400-1, 3rd ed.; International Electrotechnical Commission: Geneva, Switzerland, 2005.

(C) 2012 by the authors; licensee MDPI, Basel, Switzerland. This article is an open access article distributed under the terms and conditions of the Creative Commons Attribution license (http://creativecommons.org/licenses/by/3.0/). 